\title{
Impacto da salinidade no desenvolvimento e crescimento de mudas de carnaúba (Copernicia prunifera (Miller) H.E.Moore) ${ }^{1}$
}

Samia J. R. H olanda ${ }^{2}$, Francisca S. de Araújo², Maria I. G allão² \& Sebastião Medeiros Filho ${ }^{3}$

\section{RESU MO}

Identificar o impacto da salinidade no desenvolvimento e crescimento de espécies resistentes a altas concentrações salinas é de fundamental importância para a recuperação de áreas salinizadas do semiárido nordestino brasileiro. Visando contribuir para a resolução desta problemática, o presente trabalho avaliou o efeito de diferentes níveis de salinidade para o desenvolvimento e o crescimento da carnaúba, espécie nativa e de extremo valor econômico para a região. O s níveis analisados foram: 0, 25, 50, 100 $\mathrm{mM}$ de $\mathrm{NaCl}$, correspondente a uma condutividade elétrica de $2.0,4.6,7.1,9.6,12 \mathrm{dS} \mathrm{m}^{-1}$, respectivamente. U tilizou-se o delineamento inteiramente casualisado, com cinco tratamentos e quatro repetições, e se analisaram as variáveis altura da parte aérea, largura da parte aérea da folha, comprimento da raiz principal, peso da matéria seca, razão da matéria seca parte aérea/raiz e taxa de sobrevivência. $0 \mathrm{~s}$ tratamentos com 25 e $50 \mathrm{mM}$ de $\mathrm{NaCl}$ não afetaram a sobrevivência inicial da planta. Concentrações maiores ou iguais que $75 \mathrm{mM}$ de $\mathrm{NaCl}$ reduziram a produção de biomassa e a taxa de sobrevivência, em quase $50 \%$; portanto, a produção de plantas nesses níveis de sal não é recomendada.

Palavras-chave: taxa de crescimento relativo, estresse salino, halófita

\section{Impact of salinity on development and growing of 'carnaúba' (Copernicia prunifera (Miller) H.E. Moore) seedlings}

\begin{abstract}
To identify the impact of salinity on the development and growth of species resistant to high salt concentration is fundamental for restoration of salty areas in the Northeast brazilian semi-arid region. Seeking to solve this problem this work evaluated the effect of different salt levels on the development and growth of 'carnauba', a native species with high economical value to the region. The levels analyzed were: $0,25,50,75$ and $100 \mathrm{mM}$ of $\mathrm{NaCl}$, corresponding to an electrical conductivity of $2.0,4.6,7.1,9.6$ and $12 \mathrm{dS} \mathrm{m}^{-1}$, respectively. A completely randomized experimental design with five treatments and four replicates was used. The analyzed variables were aerial height, aerial width, main root length, dry weight, aerial/root ratio and survival rate. Treatments with 25 and $50 \mathrm{mM}$ of $\mathrm{NaCl}$ did not affect the initial plant survival. Concentration levels greater or equal to $75 \mathrm{mM}$ of $\mathrm{NaCl}$ reduced the biomass production and the survival rate in almost 50\%. Therefore, plant production at these salt levels is not recommended.
\end{abstract}

Key words: relative growth rate, salt stress, halophytic

\footnotetext{
${ }^{1}$ Parte da Dissertação de Mestrado do primeiro autor, apresentada ao Mestrado em Desenvolvimento e Meio Ambiente (PRODEMA) da Universidade Federal do Ceará

2 D B/U FC, Campus do Pici, Bloco 906, CP 6021, CEP 60455-970, Fortaleza, CE. Fone: (85) 3366-9805. E-mail: edybel@ufc.br e tchesca@ufc.br ${ }^{3}$ DF/UFC, CEP 60455-970, Fortaleza, CE. Fone: (85) 3366-9731. E-mail: filho@ufc.br
} 


\section{INTRODUÇÃO}

Segundo Taiz \& Zeiger (2009) as plantas de ambientes salinos podem ser divididas em dois grandes grupos de tolerância: halófitas - as que vivem em solos com alta concentração de sais, e glicófitas - as que apresentam menor resistência à salinidade. As halófitas apresentam tolerância ao sal devido à sua capacidade de compartimentalização dos íons no vacúolo da célula. Esta resistência a salinidade se deve à habilidade de evitar que elevadas quantidades de sal, provenientes do substrato, alcancem o protoplasma e, por meio de regulação salina, de tolerar os efeitos tóxicos e osmóticos associados ao aumento na concentração de sais (Larcher, 2000). As glicófitas, quando submetidas a altas concentrações de sais, indicam sinais de inibição do crescimento, descoloração foliar e perda de peso seco, sendo a inibição do crescimento o sintoma mais característico (Munns, 2002).

A inibição de crescimento em glicófitas se dá pela redução da habilidade de absorção de água, o que resulta em uma série de alterações metabólicas semelhantes às de plantas submetidas ao estresse hídrico (Munns, 2002). A redução na absorção de água devido aos efeitos da salinidade, segundo Prisco (1980), resulta de duas causas principais: a) do potencial de pressão, insuficiente para promover o aumento no volume celular e b) da extensibilidade da parede celular, tão baixa que, mesmo havendo absorção de água, o gradiente de potencial de pressão não é suficiente para romper a resistência oferecida pela parede ao aumento em volume das células, por outro lado, segundo Munns (2002), o NaCl altera o metabolismo do sistema radicular, especialmente a atividade de certas enzimas ocasionando redução na síntese e translocação de hormônios sintetizados na raiz, necessários ao metabolismo foliar, em consequência, haverá diminuição no crescimento das folhas e, assim, diminui a área fotossintética da planta e acelera o processo de envelhecimento dos órgãos.

O semiárido nordestino enfrenta, atualmente, um problema de salinização do solo em função de medidas de irrigação (Oliveira et al., 2007). Em todo o mundo a pressão por água de boa qualidade e expansão das áreas agrícolas tem gerado a necessidade do uso de águas de qualidade marginal na irrigação (Zeng et al., 2001). Neste contexto, é grande o potencial de uso de águas salinas na agricultura, contanto que sejam adotadas práticas adequadas de manejo da irrigação (Aldesuquy \& Ibrahim, 2001; Tester \& Davenport, 2003).

A salinidade, tanto de solos como de águas, é uma das principais causas de queda do rendimento das plantas devido aos efeitos de natureza osmótica, tóxica e/ou nutricional, afetando processos metabólicos vitais, como fotofosforilação, cadeia respiratória, assimilação do nitrogênio e metabolismo das proteínas (Munns, 2002; Tester \& Davenport, 2003); entretanto, os efeitos dependem de muitos outros fatores, como espécie, cultivar, estádio fenológico, características dos sais, intensidade e duração do estresse salino, manejo cultural e da irrigação e condições edafoclimáticas (Tester \& Davenport, 2003). Várias espécies podem até mesmo ser favorecidas quando expostas a concentrações salinas de $\mathrm{NaCl}$ (Tester \& Davenport, 2003). Para a recuperação de tais áreas e visando a um uso sustentável da biodiversidade local, é essencial conhecer espécies nativas com potencial econômico e tolerantes a solos salinizados.

Observa-se, no semiárido do nordeste brasileiro, que a carnaúba ocorre em áreas alagáveis com solos halomórficos, incluindo-se áreas de vegetação ciliar (Arruda \& Calbo, 2003). Em virtude da ocorrência natural a esses tipos de solo, esperase que esta espécie apresente características de plantas halófitas e, consequentemente, possa ser utilizada como uma das espécies para a revegetação de áreas com solos salinizados no semiárido brasileiro.

O trabalho foi desenvolvido com o objetivo de avaliar o efeito da salinidade induzida através de soluções de $\mathrm{NaCl}$ conhecida sobre o crescimento e o desenvolvimento inicial de plântulas de Copernicia prunifera, através das variáveis que destacam a sensibilidade da espécie ao $\mathrm{NaCl}$ destacando, assim, os níveis de condutividade elétrica de maior e menor resistência.

\section{Material e mÉtodos}

O experimento foi conduzido em um viveiro no Campus do Pici da Universidade Federal do Ceará $\left(03^{\circ} 45^{\prime}\right.$ S, $38^{\circ} 33^{\prime}$ W), no período de setembro/2005 a janeiro/2006, no qual a média de temperatura e umidade relativa do ar foi de $26,8^{\circ} \mathrm{C}$ e $79 \%$, respectivamente.

As sementes utilizadas foram obtidas de frutos coletados em fase de maturação, com coloração da casca verde-amarelado de uma população nativa no município de Novo Oriente, CE, em dezembro de 2004. Esses frutos foram acondicionados em sacos plásticos e transportados para o Laboratório de Análise de Sementes do Departamento de Fitotecnia, da Universidade Federal do Ceará, em Fortaleza, CE, onde foram beneficiados e armazenados durante nove meses. Para maiores detalhes sobre o procedimento de beneficiamento e armazenagem, atente-se para Schumacher et al. (2002).

Após o beneficiamento as sementes foram submetidas ao processo de pré-embebição em bandejas plásticas, onde permaneceram pelo tempo necessário à emissão da protrusão do pecíolo cotiledonar (Meerow, 2004), em seguida, lotes foram selecionados para semeadura, padronizados pelo comprimento do pecíolo cotiledonar $(\leq 4 \mathrm{~mm})$. As sementes pré-germinadas foram semeadas em posição horizontal na profundidade de 2 $\mathrm{cm}$, em número de duas por recipiente (saco de polietileno preto preenchidos com areia grossa) e submetidas diariamente a irrigação com água natural da torneira.

Com o objetivo de padronização dos tamanhos das plântulas após 60 dias de crescimento, de cada saco se excluiu uma das plântulas, deixando-se apenas as que apresentavam entre 13 a $16 \mathrm{~cm}$ de comprimento da parte aérea (CRa). No caso das duas plantas apresentarem o mesmo comprimento a escolha foi aleatória. Adotou-se o delineamento em bloco casualizado (Vieira \& Carvalho, 1994) e após seleção de 300 plântulas entre 13-16 cm, elas foram divididas aleatoriamente em cinco tratamentos com 60 plântulas cada um aplicando-se-lhes os seguintes níveis de $\mathrm{NaCl}$ comercial, isento de iodo: 0, 25, 50, 75 e $100 \mathrm{mM}$, correspondendo aos valores de condutividades

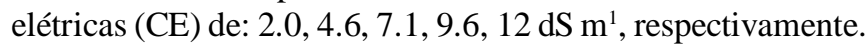
Cada tratamento foi composto de quatro repetições de 15 plântulas. 
As plântulas foram regadas diariamente no mesmo horário, pelo tempo de 60 dias, com a mesma quantidade de solução. A solução de cada tratamento também foi preparada todos os dias, enquanto a aplicação da solução foi gradativa a cada parcela, isto é, do menor para o maior nível de salinidade. Já para o preparo das soluções aplicadas em cada tratamento, além do cálculo da quantidade de água utilizada em cada saco empregou-se, também, o peso atômico do $\mathrm{NaCl}$. Após este acréscimo diário os substratos foram mantidos com $15 \%$ da capacidade de campo (cc) com o intuito de atingir o total de $60 \%$ cc estimando-se, a partir daí, o índice de evaporação da água nos tratamentos. Dessa forma obteve-se para o cálculo da capacidade de campo, a curva de retenção de água do substrato (Brasil, 1992).

O comprimento da parte aérea $(\mathrm{CRa})$ das plantas foi medido toda semana e, concomitantemente, observava-se o aparecimento de sintomas de estresse. Para análise total do efeito das diferentes concentrações de sais no final do experimento, foram medidos: largura da parte aérea da folha (Lra); comprimento da raiz principal (CRp); peso da matéria seca (PMS); razão da matéria seca parte aérea/raiz (PAR) e taxa de sobrevivência (TS), conforme Benicasa (1988). Para constatar se, na verdade, os resultados das variáveis analisadas apresentavam distribuição normal a priori, fez-se o teste de homogeneidade de variância e, em seguida, a análise de variância (ANOVA) (Zar, 1984) para verificar se os resultados dos diferentes tratamentos foram estatisticamente diferentes entre si. A posteriori, a significância das diferenças entre as médias dos tratamentos foi testada pelo teste de Tukey $5 \%$ de probabilidade (Zar, 1984).

\section{RESULTADOS E DISCUSSÃO}

Nota-se, com base na Tabela 1 , que a média do comprimento da folha 2 foi mais afetada pela salinidade que a do comprimento da folha 1. As plântulas submetidas ao estresse salino indicaram, a partir do tratamento $50 \mathrm{mM}$ de $\mathrm{NaCl}$, redução significativa na média de crescimento da folha 2 , enquanto a folha 1 não foi afetada, provavelmente por já ter atingido a maturidade; no tratamento controle $(0 \mathrm{mM}$ de $\mathrm{NaCl})$, as folhas 1 e 2 atingiram 17 e $11,7 \mathrm{~cm}$ de comprimento, respectivamente; nos tratamentos de 75 e $100 \mathrm{mM}$ de $\mathrm{NaCl}$, a folha 2 mostrou apenas 10 e $9 \mathrm{~cm}$ de comprimento enquanto a folha 1 apresentou comprimento de 16,7 e $15,5 \mathrm{~cm}$, respectivamente, resultado este similar ao do tratamento controle (Figura 1). A partir da terceira semana de experimento a folha 1 cessou o crescimento do comprimento (Figura 1).

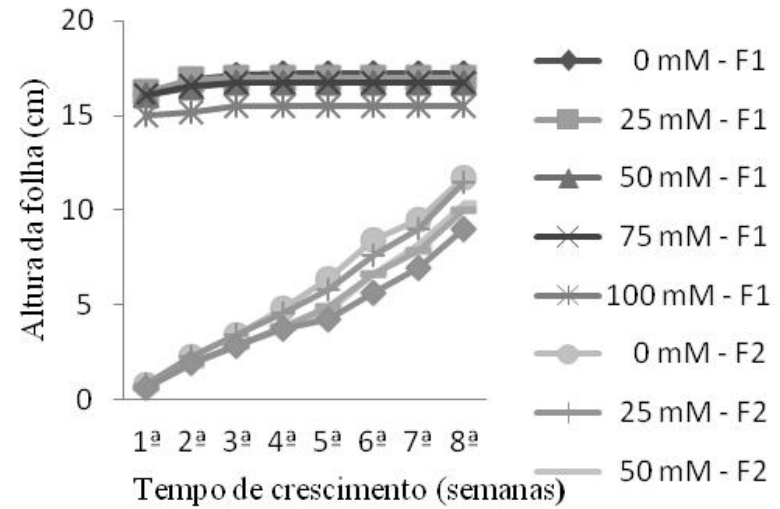

Figura 1. Variação na altura da folha 1 e folha 2 de Copernicia prunifera em relação ao crescimento semanal, a partir do tempo zero

Quanto à largura da folha 2, as médias dos tratamentos 0 $\mathrm{mM}$ de $\mathrm{NaCl}, 25,50$ e $75 \mathrm{mM}$ de $\mathrm{NaCl}$ não foram estatisticamente diferentes entre si (Tabela 1) porém houve diferença entre os tratamentos 0,25 e $100 \mathrm{mM}$. A largura média da folha 2 no tratamento $25 \mathrm{mM}$ foi $22 \%$ maior que a do tratamento $100 \mathrm{mM}$ (Tabela 1), a folha 1 morreu aos 20 dias de tratamento e, portanto, não foram tabelados os dados de largura.

Embora a carnaúba ocorra naturalmente em solos halomórficos, a redução no crescimento e desenvolvimento inicial durante este experimento demonstra que a espécie não se comporta como planta halófita, redução que se deve, possivelmente, à "seca fisiológica" provocada pela alta concentração de sais no solo, com diminuição na permeabilidade do sistema radicular para água. Munns (2002) ressaltou que o $\mathrm{NaCl}$ altera especialmente a atividade de certas enzimas e, com isto, reduz a síntese e a translocação de hormônios sintetizados na raiz, necessários ao metabolismo foliar, o que resulta em menor crescimento foliar e, assim, menor a área fotossintética da planta. Além disso, a redução no crescimento da planta se deve à menor taxa fotossintética diária em virtude do fechamento mais cedo dos estômatos em consequência da seca fisiológica, fato comum em plantas que ocorrem em solos com altas concentrações de sais de ambiente com alta demanda evaporativa e luz solar intensa, situação típica do semiárido brasileiro (Prisco, 1980). Ressalta-se que apenas o tratamento $75 \mathrm{mM}$ de $\mathrm{NaCl}$ afetou o comprimento da raiz principal (Tabela 1) constatando-se diminuição de $25 \%$ em relação ao controle.

Em condições naturais, Gomes (1946) verificou que a carnaúba desenvolve um rápido e vigoroso sistema radicular pois, ao emergir a primeira folha, após 40 dias da semeadura, a

Tabela 1. Comprimento da parte aérea ( $C R a)$ da folha 1 (CRaf1) e folha 2 (CRaf2), Largura da parte aérea da folha 2 (LRaf2) e Comprimento da raiz principal (CRp), de plantas de Copernicia prunifera cultivadas em diferentes níveis de $\mathrm{NaCl}$ aos 60 dias de estresse salino

\begin{tabular}{|c|c|c|c|c|c|c|c|c|}
\hline \multirow{2}{*}{$\begin{array}{l}\mathrm{NaCl} \\
(\mathrm{mM})\end{array}$} & \multicolumn{2}{|c|}{ CRaf1 } & \multicolumn{2}{|c|}{ CRaf2 } & \multicolumn{2}{|c|}{ LRaf2 } & \multicolumn{2}{|c|}{ CRp } \\
\hline & $(\mathrm{cm})$ & $(\%)$ & $(\mathrm{cm})$ & $(\%)$ & $(\mathrm{cm})$ & $(\%)$ & $(\mathrm{cm})$ & (\%) \\
\hline 0 & $17,0 a$ & 100 & $11,7 \mathrm{a}$ & 100 & $0,8 a b$ & 89 & 38,55 a & 100 \\
\hline 25 & $17,0 \mathrm{a}$ & 100 & $11,5 \mathrm{a}$ & 92 & $0,9 \mathrm{a}$ & 100 & $31,97 a b$ & 83 \\
\hline 50 & $16,7 a$ & 94 & $10,3 a b c$ & 83 & $0,8 a b$ & 89 & $33,68 a b$ & 87 \\
\hline 75 & $16,7 a$ & 94 & $10,0 \mathrm{bc}$ & 83 & $0,8 a b$ & 89 & $29,07 \mathrm{~b}$ & 75 \\
\hline 100 & $15,5 a$ & 88 & $9,0 \mathrm{c}$ & 75 & $0,7 \mathrm{~b}$ & 78 & $35,77 a b$ & 93 \\
\hline
\end{tabular}


raiz já atingia $15 \mathrm{~cm}$ de profundidade e, ao final de 60 dias, a folha apresentava $22 \mathrm{~cm}$ de comprimento e a raiz $50 \mathrm{~cm}$ de profundidade, que continuou crescendo, mesmo ao longo de vários meses de seca. Este rápido crescimento das raízes em condições naturais pode potencializar o aumento da área de absorção e, então, amenizar os efeitos da seca fisiológica, o que pode justificar a sua ocorrência natural em solos halomórficos, embora a carnaúba apresente características morfológicas foliares que podem ser consideradas xerofíticas, tais como: reentrâncias e saliências nos espaçamentos da parede ventral, parede dorsal uniforme e fina, lumen das células guardiãs, em corte transversal, um pouco triangular exibindo, no vértice, uma invaginação, que o prolonga até quase os limites da parede externa e estômatos em maior quantidade na superfície abaxial (Arraes et al., 1966) facilitando sua ocorrência em solos halomórficos em clima semiárido.

Apenas os tratamentos 75 e $100 \mathrm{mM}$ de $\mathrm{NaCl}$ reduziram a produção de matéria seca de plântulas em todos os tratamentos (Tabela 2). A biomassa da parte aérea foi 7 e $16 \%$ menor em relação ao controle enquanto a biomassa da raiz, nas concentrações de 75 e $100 \mathrm{mM}$ de $\mathrm{NaCl}$, foi cerca de 21 e $18 \%$ menor, respectivamente, proporcionalmente, a parte aérea mostrou maior desenvolvimento que a raiz.

Tabela 2. Peso da matéria seca da folha (PM Sf), peso da matéria seca da raiz (PMSr) e razão parte aérea/raiz (PAR) de plantas de Copernicia prunifera cultivadas em diferentes níveis de $\mathrm{N} \mathrm{aCl}$ aos 60 dias de estresse salino

\begin{tabular}{|c|c|c|c|c|c|c|}
\hline \multirow{2}{*}{$\begin{array}{l}\mathrm{NaCl} \\
\text { (mM) }\end{array}$} & \multicolumn{2}{|c|}{ PMSf } & \multicolumn{2}{|c|}{ PMSr } & \multicolumn{2}{|c|}{ PAR } \\
\hline & (g) & (\%) & (g) & (\%) & (g) & (\%) \\
\hline 0 & $6,49 \mathrm{a}$ & 100 & $13,77 \mathrm{a}$ & 100 & $2,12 \mathrm{a}$ & 100 \\
\hline 25 & $6,37 a b$ & 98 & $11,76 \mathrm{ab}$ & 85 & $1,85 \mathrm{ab}$ & 87 \\
\hline 50 & $6,18 \mathrm{ab}$ & 95 & $11,93 a b$ & 87 & $1,93 a b$ & 91 \\
\hline 75 & $6,02 b$ & 93 & $10,83 \mathrm{~b}$ & 79 & $1,79 a b$ & 85 \\
\hline 100 & $5,45 \mathrm{c}$ & 84 & $11,33 \mathrm{~b}$ & 82 & $2,07 a b$ & 98 \\
\hline
\end{tabular}

Valores dentro de uma mesma coluna seguidos da mesma letra, não diferem estatisticamente em nível de $5 \%$ de probabilidade pelo teste de Tukey

O menor crescimento da raiz em relação à parte aérea em espécies de palmeiras, segundo Meerow (2004), se deve ao fato das sementes conterem ricas substâncias de reserva, capazes de nutrir a parte aérea até 90 dias; desta forma, o desenvolvimento inicial da parte aérea é pouco afetado pela diminuição de absorção de nutrientes pela raiz, característica de sementes de palmeiras (Meerow, 2004) associadas ao rápido crescimento inicial do sistema radicular de Copernicia prunifera condições naturais (Gomes, 1946) que devem favorecer o estabelecimento de suas plântulas em regiões de climas áridos e semiáridos.

Marinho et al. (2005) observaram redução mais acentuada do sistema radicular nas plântulas de coco em níveis elevados de salinidade; os autores sugerem que o crescimento maior da parte aérea possa ser decorrente do tipo de semente rica em substâncias de reserva; outro fator também considerado pelos autores é o tipo de folha do coqueiro, com tecidos do limbo ricos em esclerênquima, epiderme espessa e de textura grossa tendo, inclusive, estômatos localizados apenas na face inferior o que, naturalmente, resulta em menor perda de água por transpiração. Além de Copernicia prunifera, em estudos já realizados em outras duas palmeiras submetidas a aumento de salinidade, tais como a pupunheira (Bactris gasipaes H. B. K.) (Fernandes et al., 2003), o alho (Amorim et al., 2002) e em aceroleira (Gurgel et al., 2003) também se verificou redução de crescimento da raiz; essas espécies de palmeira não devem, provavelmente, resistir a solos com alta salinidade. Fernandes et al. (2003) e Marinho et al. (2005) avaliaram os efeitos da irrigação com água nas concentrações de sais $\mathrm{CEa}=2,2,5,10$, 15 e $20 \mathrm{dS} \mathrm{m}^{-1}$ sobre a germinação e o crescimento inicial por 120 dias após semeadura (fase I) e constataram que o sistema radicular foi a variável mais afetada.

A taxa de sobrevivência de plantas (folha 1 e/ou 2) foi de $95 \%$ ao final dos 60 dias de experimento, em que as folhas 1 e 2 responderam diferentemente aos tratamentos. A taxa de sobrevivência da folha 1 foi de $5 \%$ enquanto a taxa sobrevivência da folha 2 foi de $95 \%$. Não foram observadas injúrias ou morte nas folhas das plântulas controle.

A folha 1 (TSF1) foi a mais afetada pela salinidade; aos 20 dias de estresse salino as plântulas submetidas a 75 e 100 mM de $\mathrm{NaCl}$ já apresentavam sinais de diminuição fotossintética pelo amarelecimento das folhas; ao final de 60 dias, as folhas 1 , submetidas a esses dois tratamentos, apresentaram 32 e 50\% de mortalidade, respectivamente (Figura 2); na folha 2 a maior porcentagem de mortalidade (13\%) ocorreu no tratamento de $100 \mathrm{mM}$ de $\mathrm{NaCl}$ (Figura 2).

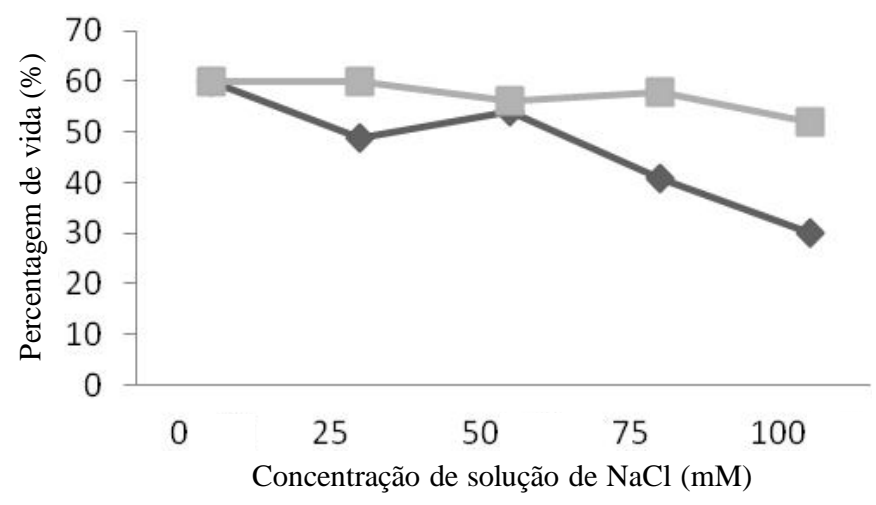

Figura 2. Percentagem de sobrevivência da folha de Copernicia prunifera quando submetida aos diferentes níveis de sal inidade aos 60 dias de estresse salino, sendo:

- $\Delta$ - folha 1; - - - folha 2

$\mathrm{O}$ alto índice de mortalidade da primeira folha (95\%) foi devido, sem dúvida, à diminuição da água disponível no solo, pelo aumento de soluto, diminuindo o potencial osmótico e, em consequência, o potencial hídrico da planta, afetando a área fotossintetizante da carnaúba e acarretando morte prematura da primeira folha. Taiz \& Zeiger (2009) explicam que a fotossíntese é inibida em altas concentrações de $\mathrm{Na}^{+}$e/ou $\mathrm{Cl}^{-}$, visto que se acumulam nos cloroplastos, possíveis de afetar tanto o metabolismo do carbono como a fotofosforilação. As injúrias induzidas por sais podem ocorrer não somente devido a efeitos osmóticos e oxidativos, mas, também, por efeitos tóxicos e de deficiência de nutrientes (Sivritepe et al., 2003; Souza et al., 2007). Se a concentração excede a tolerância da planta, danos serão produzidos, como queimaduras e necroses nas folhas acompanhado, geralmente, por desfolhação 
prematura (Munns, 2002; Bezerra et al., 2005) o que explica a morte prematura das folhas de carnaúba quando submetidas aos níveis de 75 e $100 \mathrm{~mol} \mathrm{~m}^{-3}$ de $\mathrm{NaCl}$.

Embora a carnaúba seja naturalmente encontrada em solos halomórficos, o limite de tolerância à salinidade encontrado neste estudo é inferior ao já registrado em espécies de dicotiledôneas. Em goiabeira (Psidium guajava) submetida a estresse salino com $\mathrm{NaCl}$, Távora et al. (2001) detectaram que a sobrevivência das plantas não foi afetada até o nível de estresse salino de $125 \mathrm{mmol} \mathrm{l}^{-1} \mathrm{de} \mathrm{NaCl}$, resultado este superior ao limite encontrado para carnaúba, porém se deve ressaltar que, embora haja plantas com potencial econômico de maior tolerância ao estresse salino que a carnaúba, como é o caso da goiabeira, além desta espécie tolerar níveis intermediários de salinidade ( 25 e $50 \mathrm{mM}$ de $\mathrm{NaCl}$ ), como constatado neste trabalho, seu desenvolvimento inicial não é afetado pelo alagamento, como demonstrado por Arruda \& Calbo (2003), justificando sua ocorrência natural em solos halomórficos submetidos a períodos de alagamento (chuva) e déficit hídrico (seca) e o seu possível plantio em áreas de várzeas salinizadas.

Com base neste trabalho os melhores resultados para o plantio de mudas com relação ao estresse salino, foram em 0 , 25 e $50 \mathrm{mM}$ de $\mathrm{NaCl}$, em especial $25 \mathrm{mM}$, haja vista o melhor desenvolvimento da largura foliar neste nível de salinidade, não é aconselhável seu plantio em áreas que apresentem nível de salinidade no solo maior ou igual a $75 \mathrm{mM}$ de $\mathrm{NaCl}$, pois quando submetidas a esses níveis apresentam desenvolvimento comprometido e, possivelmente, a sobrevivência da planta; referido comportamento é similar ao encontrado em plantas classificadas como glicófitas, que não resistem a altas concentrações salinas (Munns, 2002).

\section{ConClusõEs}

1. Os melhores resultados para a produção de mudas de Copernicia prunifera foram os de 0,25 e $50 \mathrm{mM} \mathrm{de} \mathrm{NaCl}$, em especial $25 \mathrm{mM}$, haja vista o melhor desenvolvimento da largura foliar neste nível de salinidade.

2. Por tolerar apenas níveis intermediários de salinidades, a Copernicia prunifera pode ser classificada como glicófita.

3. Para plântulas de Copernicia prunifera com até dois meses de idade é recomendável seu plantio no aproveitamento de áreas salinizadas que apresentem condutividade elétrica de até $3 \mathrm{dS} \mathrm{m}^{-1}$.

\section{Agradecimentos}

Os autores agradecem à Fundação Cearense de Amparo à Pesquisa (FUNCAP), pela bolsa concedida ao primeiro autor, e ao CNPq, pelo auxílio concedido através do Edital Universal (Processo n. 472024/2004). Ao pesquisador da Embrapa Agroindústria Tropical/CE, Dr. Edy Sousa de Brito, pela colaboração nas análises estatísticas e elaboração do abstract; ao Agrônomo do Departamento de Fitotecnia/UFC, Dr. João Batista Santiago Farias, pela ajuda na montagem do experimento. Enfim, ao Prof. Dr. Alexandre Fadigas de Souza, pelas sugestões e críticas.

\section{LITERATURA CITADA}

Aldesuquy, H. S.; Ibrahim, A. H. Water relations, abscisic acid and yield of wheat plants in relation to the interactive effect of wheat plants in relation to the interactive effect of seawater and growth bioregulators. Journal of Agronomy and Crop Science, v.187, p.97-104, 2001.

Amorim, J. R. A.; Fernandes, P. D.; Gheyi, H. R.; Azevedo, N. C. Efeito da salinidade e modo de aplicação da água de irrigação no crescimento e produção de alho. Pesquisa Agropecuária Brasileira, v.37, p.167-176, 2002.

Arraes, M. A. B.; Machado, R. D.; Nepomuceno, V. A. Sobre a anatomia da folha da carnaubeira [Copernicia prunifera (Miller)] Moore, HE. Anais da Academia Brasileira de Ciências, v.38, p.73-82, 1966.

Arruda, G. M. T.; Calbo, M. E. R. Efeitos da inundação no crescimento, trocas gasosas e porosidade radicular da carnaúba (Copernicia prunifera (Mill.) H.E. Moore). Acta Botânica Brasileira, v.18, p.219-224, 2003.

Benicasa, M. M. P. Análise de crescimento de plantas (noções básicas). Jaboticabal: UNESP. 1988. 42p.

Bezerra, M. A.; Lacerda, C. F. de; Prisco, J. T.; Gomes Filho, E. Crescimento e fotossíntese de plantas jovens de cajueiro anãoprecoce sob estesse salino. Revista Brasileira de Engenharia Agrícola eAmbiental, v.9, p.90-94, 2005.

Brasil. Ministério da Agricultura e Reforma Agrária. Regras para Análise de Sementes. Brasília: SNDA/DNDV/CLAV, 1992.365p.

Fernandes, A. R.; Carvalho, J. G. de; Curi, N.; Guimarães, P. de T. G.; Pinto, J. E. B. P. Crescimento de mudas de pupunheira (Bactris gasipaes H. B. K.) sob diferentes níveis de salinidade. Ciência Agrotécnica, v.27, n.2, p.278-284, 2003.

Gomes, R. P. A germinação da carnaubeira. Rodriguésia, v.10, p.1-5, 1946.

Gurgel, M. T.; Fernandes, P. D.; Gheyi, H. R.; Santos, F. J. S.; Nobre, R. G. Índices fisiológicos e de crescimento de um porta-enxerto de aceroleira sob estresse salino. Revista Brasileira de Engenharia Agrícola e Ambiental, v.7, p.451456, 2003.

Larcher, W. Ecofisiologia vegetal. São Carlos: RiMa, 2000. 531p.

Marinho, F. J. L.; Gheyi, H. R. Fernandes, P. D. Germinação e formação de mudas de coqueiro irrigadas com águas. Revista Brasileira de Engenharia Agrícola e Ambiental, v.9, p.334340, 2005.

Meerow, A. W. Palm seed germination. 2004. In: IFAS Cooperative. Nevada: University of Nevada. http:// edis.ifas.ufl.edu/EP238. 24 Mar. 2007.

Munns, R. Comparative physiology of salt and water stress. Plant, Cell \& Environment, v.25, p.239-250, 2002.

Oliveira, A. K. C.; Silva, M. S.; Mendonça, C. E. S. Ferreira, G. B.; Chaves, V. C.; Silva, D. J. Avaliação qualitativa da água de barragens subterrâneas no semi árido nordestino brasileiro. Revista Brasileira de Agroecologia, v.2, p.14011404, 2007. 
Prisco, J. T. Alguns aspectos da fisiologia do "stress" salino. Revista Brasileira de Botânica, v.3, p.85-94, 1980.

Schumacher, M. V.; Hoppe, J. M.; Farias J. A. Manual de instruções para a coleta, beneficiamento, armazenamento e análise de sementes florestais. Projeto bolsa de sementes de espécies florestais, Santa Maria: UFSM/AFUBRA, 2002. $155 \mathrm{p}$.

Sivritepe N.; Sivritepe H. O.; Eris A. The effect of $\mathrm{NaCl}$ priming on salt tolerance in melon seedling grown under saline conditions. Scientae Horticulturae, v.97, p.229-237, 2003.

Souza, N. K. R.; Alcântara Jr., J. P.; Amorim, S. M. C. Efeito do estresse salino sobre a produção de fitomassa em Physalis angulata L. (Solanaceae). Revista Acadêmica, v.5, p.379384, 2007.
Taiz, L.; Zeiger, E. Plant physiology. 3.ed. Porto Alegre: Artmed, 2009. 719p.

Távora, F. J. A. F.; Ferreira, R. G.; Hernandez, F. F. F. Crescimento e relações hídricas em plantas de goiabeira submetidas a estresse salino com NaCl. Revista Brasileira de Fruticultura, v.2,p.441-446, 2001.

Tester, M.; Davenport, R. Na+ tolerance and $\mathrm{Na}^{+}$transport in higher plants. Annals of Botany, v.91, n.3, p.503-527, 2003.

Vieira, R. D.; Carvalho, N. M. Testes de vigor em sementes. Jaboticabal: FUNEP, 1994. 164p.

Zar, J. H. Biostatistical analysis. 2.ed. New Jersey: PrenticeHall, 1984. 718p.

Zeng, L.; Shannon, M. C.; Lesch, S. M. Timing of salinity stress affects rice growth and yield components. Agricultural Water Management, v.48, p.191-206, 2001. 